\title{
The Analysis of Light Intensity Transmission Coefficient Through Plastic Fibers for the Design of Closed Room Lighting without Electricity
}

\author{
Taat Guswantoro \\ Universitas Kristen Indonesia, Jakarta, Indonesia \\ Email: taat.guswantoro@uki.ac.id
}

\begin{abstract}
The phenomenon of total internal reflection can be used to guide the light to be transmitted from one place to another, it is applied to the guiding principle of light in fiber optics. A fiber rope made of clear plastic material with a uniform refractive index, when one end fired a beam of light then the light will be forwarded along the strap so that out at the other end. This principle can be applied as a lighting source in a closed room by passing light from the outdoors by using plastic fiber, so it doesn't need the electricity. In this study, theoretical analysis of the percentage of the intensity of light transmitted by the fiber plastic succeed as a function of the refractive index and determine the transmission coefficient for some plastic seeds are eligible to be used as a plastic fiber light successor. From the results of deriving the equation, the light transmission coefficient of plastic is $T=1-\sqrt{2-n^{2}}$ and the terms of plastic seeds that can be used as a plastic fiber are having a refractive index $1<n \leq \sqrt{2}$. Based on refractive index data from profesionalplastics, the maximum transmission coefficient value for Ethylene Tetrafluoro Ethylene Copolymer is $82.23 \%$ and the minimum transmission value of Fluorinated Ethylene Propylene Copolymer is 55.99\%.
\end{abstract}

Keywords: Fiber Optics, Light Guides, Plastic Fibers, Transmission Coefficient.

\section{A. INTRODUCTION}

Lighting and air circulation are things that need to be considered in the design of a room to support the activities of someone who works in the room. Good air circulation will guarantee the availability of oxygen used for someone's activities, while good lighting will cause a person to work more optimally. Therefore usually in a room there is a window or other ventilation so that air and light can enter the room. In addition to air circulation, room temperature also affects the performance of people who are indoors, so that currently many air conditioners and humidifiers are used to regulate the air condition in the room.

Indoor lighting can be done in two ways, namely by utilizing sunlight during the daytime, or by artificial lighting using electric lights. Natural lighting with the sun can be done by using a glass window, where the glass is directly exposed to sunlight so that light can penetrate the room, but this cannot be done in a closed room in the middle of the building, because there is no side dealing with sunlight from outside. Lighting in closed spaces usually uses electric lights.

The use of electric lamp for lighting in a closed room can increase the electrical load in the room. One of the ways to save electrical energy to fulfill lighting 
in a closed room is with sunlight-guide reflector. By using this sunlight guide reflector, sunlight can be exposed into the closed room so that it can illuminate it. Sunlight passing through this guide attenuates at $0.77 \mathrm{~dB} / \mathrm{m}$. So that sunlight is transmitted by $33 \%$. Another weakness of this light guide model is aesthetics and its installation (Fachrizal, 2008).

Guiding the light is more effective by total reflection principle as applied to optical fibers. Total reflection can occur when light propagates towards a medium that has a lower refractive index with an incidence angle that is more than its critical angle (Jenkins etal, 1976). Optical fiber is designed so that the light entering into it undergoes total reflection in optical fibers, so that light will come out from the other end of the optical fiber with little attenuation.

Guiding the light waves using optical fiber, the intensity of sunlight that penetrates into the room depends on the incidence angle of light into the optical fiber. As is well known that the pseudo daily movements of the sun will cause the changing of this angle. To optimize the angle of the light guide, a Solar Illumination is used which utilizes a solar tracer system to get the direction of the light source, resulting in an efficiency of 12\% (Suyatno et al., 2011).

Optical fiber technology is a technology to faster data transfer by utilizing light waves, so that it will feel very expensive when used only in closed room lighting. The principle of perfect reflection in optical fibers can be adopted as a light guide using nylon fibers, such as nylon lamp ornaments. In this nylon lamp, a set of nylon fibers is one end placed on a light source in the form of a colorful LED, while the other end is left unraveling, then colorful light will emerge from the free end of the nylon fiber.

By using the principle on this nylon lamp, a cheap light guide will be obtained using transparent fibers from nylon or plastic materials. In this study we will mathematically test the transmission coefficients of various types of plastic materials used as light guide fibers, using the principle of perfect reflection in the fiber.

\section{B. METHOD}

This research was conducted using mathematical testing. By using the principle of total reflection, it can be obtained that the refractive index of material that can be used as a light guide fiber material, also obtained the maximum incidence angle requirements of the light that can be perfectly reflected in the fiber. By substituting the maximum angle value in the three-dimensional form so that it becomes to form of a solid angle, it can be determined that the equation to calculates the amount of light transmission coefficient by comparing the angle of the space with the half-sphere space angle. Furthermore, the plastic seed refractive index data obtained from professionalplastic's datasheet is substituted in the transmission coefficient equation to obtain plastic seed material which has the largest transmission coefficient. 


\section{RESULTS AND DISCUSSION}

\section{Differences in Guiding Light on Optical Fibers and Plastic Fibers}

Commercial optical fiber is used to transmit data quickly by utilizing light waves so that the transferred data will move according to the speed of light. The main part of optical fiber in guiding light waves is the core and the cladding, that made of glass but have different refractive index, the core refractive index is greater than the refractive index of the cladding (Chang, 2002). Guiding light waves on optical fibers is using the principle of total reflection that experienced by the light that propagate from the core towards the cladding with incidence angles greater than the critical angle.

Light initially comes from the air and refracted enter into the core, light from the core will propagate to the boundary between the core and cladding. Then the light will experience total reflection if the incidence angle that formed by light and this boundary greater than the critical angle between the core and cladding, if less than the critical angle the light will escape leaving the optical fiber and cannot be guided to the other end of the optical fiber (Bass et al, 1995).

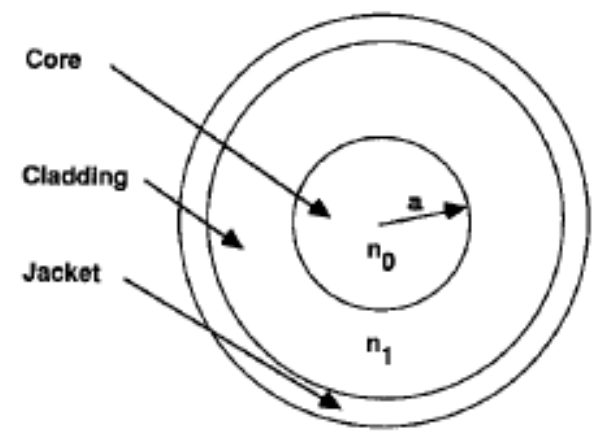

〈al

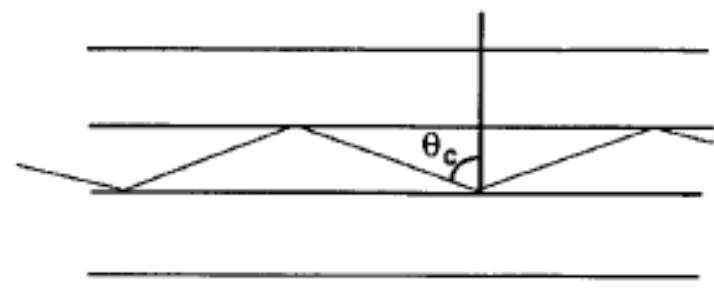

(b)

Figure 1. (a) Optical fiber sections. (b) Light wave guiding model in optical fiber (Bass etal, 1995).

In plastic fibers only consists of a part and it is assumed that the fiber is homogeneous, so that all parts of the fiber have the homogen refractive index value. Light from the air is inserted into the fiber, then it will go to the boundary between fiber and air. Guiding the light waves occurs along plastic fibers by utilizing total reflection that occurs in the boundary between plastic fibers and air. This total reflection can occur with the condition that the incidence angle from plastic fibers to the boundary between plastic and air has to be greater than the critical angle, when the incidence angle is smaller than the critical angle, the light will escape and cannot be guided to the other end of plastic fibers (Jenkins etal, 1976). 


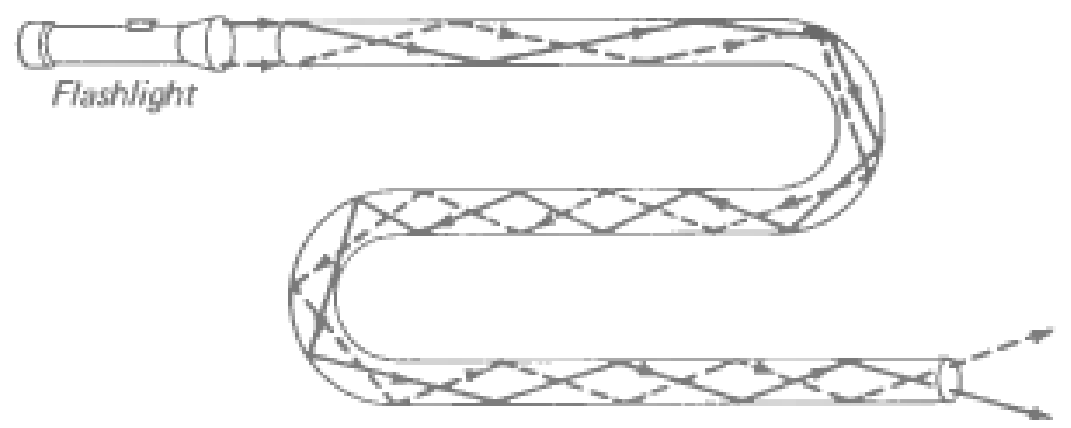

Figure 2. Light Wave Guiding Model on Plastic Fibers (Jenkins etal, 1976)

\section{Internal Total Reflection in Plastic Fiber}

An elongated tubular plastic fiber has a refractive index of $n$ with a beam of light directed into it, as shown in figure 3. Light entering the fiber by forming an incidence angle of $\theta_{i}$ will be refracted with an angle of $\theta_{r}$ so that total reflection occurs in the fiber, the refration angle must be $\left(90-\theta_{c}\right)$, where $\theta_{c}$ is the critical angle.

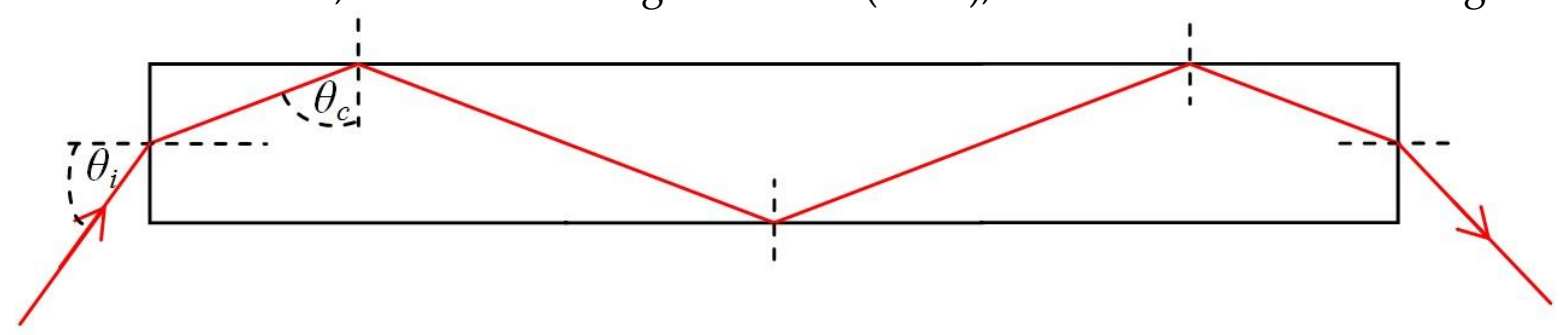

Figure 3. A beam of Light Insiding the Plastic Fibers

Assuming an air refractive index of 1 , the critical angle equations are as follows:

$\sin \theta_{c}=\frac{1}{n}$

Using Snellius's law, the equation is obtained:

$$
\begin{aligned}
& \sin \theta_{i}=n \sin \theta_{r} \\
& \sin \theta_{i}=n \sin \left(90-\theta_{c}\right) \\
& \sin \theta_{i}=n \cos \theta_{c} \\
& \sin \theta_{i}=n \sqrt{1-\sin ^{2} \theta_{c}} \\
& \sin \theta_{i}=n \sqrt{1-\frac{1}{n^{2}}} \\
& \sin \theta_{i}=\sqrt{n^{2}-1}
\end{aligned}
$$

The magnitude of the angle $\theta_{i}$ is the maximum of incidence angle into the fiber so that light can be guided along the plastic fiber, when the incidence angle greater than that angle the light will escape out from the surface of the fiber, so that it cannot be guided to the other end of plastic fiber. 
The $\sin \theta_{i}$ value has a minimum value of 0 and a maximum of 1 , so based on the equation above the requirements for plastic that can be used as fiber are as follows:

$0<\sqrt{n^{2}-1} \leq 1$

$1<n \leq \sqrt{2}$

$1<n \leq 1.4142$

Equation (3) is a refractive index requirement of plastic seeds so that total reflection can be occured in plastic fibers, so that plastic fibers can be used as light guides.

\section{Formulation of Transmission Coefficients on Plastic Fibers}

Natural light from the sun before penetrating the fiber has a divergent direction because it experiences scattering, reflection and refraction during its propagation. It can be assumed that lights leading to a point in the fiber cross-section are light that coming from various directions, as illustrated in figure 4 .

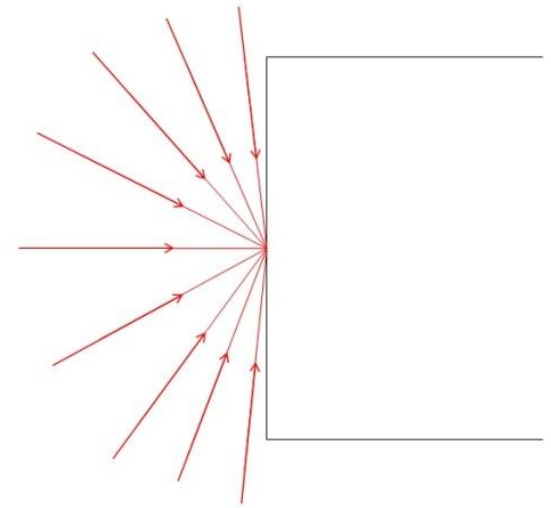

Figure 4. Illustration of Light Leading to a Point on a Cross Section of Plastic Fibers

The light that will be guided along the fiber and will reach the other end of the fiber has an incidence angle requirement as written in equation (2) so that not all of the light will be passed to the other end of the fiber.

Lights that entering fiber comes from all directions in front of the fiber crosssection, so that the space angle of the light entering one point is equal to the solid angle of the half-ball that is equal to $2 \pi$ steradian, while the light that is guided is only the light that qualified as equation (2). Figure 5, shows a geometric comparison between total light entering fiber with light that can be guided by fiber. 


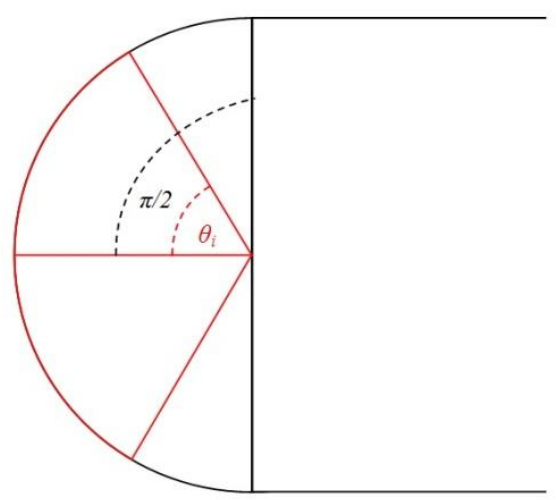

Figure 5. Comparison of Total Light Entering Fiber (half a ball) with light that can be Guided by Plastic Fibers (Ball Segment)

So to find the intensity of the transmitted light is to compare the area of the ball segment at an angle $\theta_{i}$ to the area of half the ball. The area of a ball segment can be calculated using the following integrals :

$$
\begin{aligned}
& A_{T}=2 \pi r^{2} \int_{0}^{\theta_{i}} \sin \theta d \theta \\
& A_{T}=2 \pi r^{2}\left(1-\cos \theta_{i}\right)
\end{aligned}
$$

The transmitted intensity is :

$$
\begin{aligned}
& \frac{I_{T}}{I_{0}}=\frac{A_{T}}{A_{0}}=1-\cos \theta_{i} \\
& T=1-\sqrt{1-\sin ^{2} \theta_{i}} \\
& T=1-\sqrt{1-\left(n^{2}-1\right)} \\
& T=1-\sqrt{2-n^{2}}
\end{aligned}
$$

Equation (5) is the magnitude of the light transmission coefficient on plastic fibers. The acquisition of this transmission is theoretical, while in the application there are still corrections, for example, correction due to the coefficient of absorbance of plastic material.

\section{Plastic Fiber Transmission Coefficient}

Based on equation (5) the magnitude of the transmission coefficient is a function of the refractive index of plastic material. The transmission coefficient determines the amount of light intensity that can be passed on by plastic fibers, so that the greater the transmission coefficient will be greater also the intensity of the light successfully guided. Based on equation (5) when the refractive index of plastic material is equal to $\sqrt{2}=1,4142$, then the transmission coefficient is $100 \%$ so that all the light entering the plastic fiber will be passed without decreasing intensity. So that it can be said that the ideal plastic material for plastic fibers is plastic which has a refractive index of $\sqrt{2}=1,4142$. 
Based on the Physical Properties of Plastic data released by Professional Plastic, several types of plastic material can be used as plastic fibers according to the requirements in equation (3). By substituting the refractive index value of each plastic material, the transmission coefficient of the material will be obtained. Table 1 shows some plastic materials that meet the refractive index requirements to be used as light guide plastic fibers.

Table 1. Several Plastic Materials that Qualify as Optical Fibers (Professional Plastic sources)

\begin{tabular}{llcc}
\hline No & \multicolumn{1}{c}{ Plastic Material } & $\begin{array}{c}\text { Refrative } \\
\text { Index }\end{array}$ & $\begin{array}{c}\text { Transmission } \\
\text { Coefficient }\end{array}$ \\
\hline 1 & Ethylene-Tetrafluoroethylene Copolymer & 1.403 & $82,23 \%$ \\
2 & Fluorinated Ethylene Propylene Copolymer & 1.344 & $55,99 \%$ \\
3 & Polytetrafluoroethylene & 1.380 & $69,08 \%$ \\
4 & $\begin{array}{l}\text { Tetrafluoroethyleneperfluoro (alkoxy vinyl } \\
\text { ether) - Copolymer }\end{array}$ & 1.350 & $57,87 \%$ \\
\hline
\end{tabular}

Based on the results in Table 1, the lowest transmission coefficient is for plastic from Fluorinated Ethylene Propylene Copolymer which is 55.99\%, while the highest value for plastic material from Ethylene-Tetrafluoroethylene Copolymer is $82.23 \%$. From these materials, the best material to be used as plastic fiber to guide light to obtain natural lighting for a closed room without electricity is plastic made from Ethylene-Tetrafluoroethylene Copolymer.

\section{CONCLUSION}

Plastic fibers can be used to guiding the light so that it can be applied as the lighting in a closed room to saving electricity power. The transmission coefficient of plastic material is a function of the refractive index, the ideal plastic material has a refractive index of 1.4142. Based on data on the physical properties obtained from professional plastic, the Ethylene-Tetrafluoroethylene Copolymer plastic material is the best material that can be used for plastic fibers, that has a transmission coefficient of $82.23 \%$.

\section{REFERENCES}

1. Bass, M., Van Stryland, E. W., Wolfe, W. L., \& Williams, D. R. (Eds.). (1995). Handbook of Optics: Fundamentals, techniques, and design. McGraw-Hill Professional Publishing.

2. Chang, W. S. C. (2002). Principal of Laser and Optics. Chambridge University Press.

3. Fachrizal, N. (2008). Pemandu Cahaya Matahari untuk Pencahayaan Alami di Bangunan. Jurnal Sains dan Teknologi Indonesia, 10(3), 142-148.

4. Jenkins, F. A., \& White, H. A. (1976). Fundamental of Optics Fourth Edition. McGraw-Hill: Kogakusha. 
5. Suyatno, Yudoyono, G., \& Albanna, I. (2011). Pencahayaan dalam ruang tertutup menggunakan solar illumination. Jurnal Fisika dan Aplikasinya, 7(2), 1-4.

6. https://www.professionalplastics.com/professionalplastics/PhysicalPropertiesofP lastics.pdf, accessed on July 31, 2019. 